\title{
Isotopic Method for Measurement of Calcium Absorption from the Gastro-intestinal Tract
}

\author{
G. ALAN ROSE,* D.M., F.R.I.C. ; G. W. REED, $\dagger$ M.SC. ; A. H. SMITH, $\dagger$ B.SC.
}

Brit. med. F., 1965, 1, 690-692

The study of calcium metabolism is made difficult by the fact that in the normal adult some $80 \%$ of the calcium excretion takes place via the faecal route. This means that in order to get calcium-balance data by traditional techniques it has been necessary to subject the faeces to manipulations which are not only time-consuming and liable to considerable error but disagreeable as well. With the increasing availability of isotopes of calcium suitable for clinical studies in human subjects it seems reasonable to consider their use to measure absorption of calcium from the gastro-intestinal tract. We here describe a test in which ${ }^{47} \mathrm{Ca}$ is given by mouth and the faecal radioactivity measured without further manipulation of the faeces. From these figures and the calcium intake the calcium absorbed is calculated, and this is compared with data obtained simultaneously by the usual balance techniques. This appears to be the first report in which such a comparison has been made in a reasonably large series of patients.

\section{Methods}

All the subjects were in a metabolic unit for the purpose of more prolonged balance studies. Two were obese but otherwise normal, but all the others had a metabolic bone disease which was usually osteoporosis or osteomalacia. The general conditions and methods used, and the combined use of intermittent carmine red and continuous chromium marking of stools, were as previously described by Rose (1964). In general, six-day metabolic periods were used, but occasionally four-day periods were used instead. The ${ }^{47} \mathrm{Ca}$ arrived approximately once a month and was given as soon afterwards as possible, this usually being the next day, and regardless of when the previous carmine marker had been given. Six patients received the isotope on two separate occasions four or more weeks apart. The remaining 19 patients received only one dose each.

It seemed possible that calcium absorption might vary from hour to hour during the day, and two methods of administration were therefore compared. In the one group (16 tests) the ${ }^{47} \mathrm{Ca}$ was given as a short drink during the course of breakfast; in the other group 15 tests) the ${ }^{47} \mathrm{Ca}$ was previously allowed to equilibrate with the entire milk ration for the day during which it was to be administered. There was no significant retention of ${ }^{47} \mathrm{Ca}$ on the glassware used. From the time of administration of the isotope all stools were examined for radioactivity until this had become undetectable. The stools were left in the standard cartons into which they had been placed by the nursing staff. Radioactivity was measured in a cylindrical array of G.M. counters similar to that described by Veall and Vetter (1952). The counter geometry gives uniform sensitivity of response over a volume large enough entirely to include a carton. A measured aliquot of the administered dose diluted in $250 \mathrm{ml}$. was used for calibration. Both the samples and the standard were measured within a lead container of 2-mm. wall which allows differential counting of the ${ }^{4 i} \mathrm{Ca}$ independently of the radiation from the ${ }^{47} \mathrm{Sc}$ to which the calcium isotope decays.

\footnotetext{
* University Department of Medicine, the General Infirmary at Leeds. t University Department of Medical Physics, the General Infirmary at
}

The sensitivity of our present method is such as to require of the order of $10 \mu \mathrm{c}{ }^{47} \mathrm{Ca}$ per test. In three cases, however, the radiation measurements were done with a whole-body scintillation counter, and it was then possible to use as little as $1.5 \mu \mathrm{c}$.

The percentage isotope absorption is taken to be $\frac{{ }^{47} \mathrm{Ca} \text { given }-{ }^{47} \mathrm{Ca} \text { in stools }}{{ }^{47} \mathrm{Ca} \text { given }} \times 100$. This ignores any of the ${ }^{47} \mathrm{Ca}$ resecreted into the bowel during the period of the test. The error involved will be less the less the absorption, but even when the absorption is high the error should still be small, for it has been shown by Geissberger (1952), Bellin and Laszlo (1953), and Bronner et al. (1956) that only very small fractions of intravenous doses of isotopic calcium are excreted into the bowel.

The absorption of stable calcium from the diet is taken as the product of percentage isotopic absorption and the dietary calcium. The figure obtained in this way is called the true calcium absorption, in clear distinction from the net calcium absorption obtained by subtracting from the dietary calcium the value of faecal calcium obtained during the same metabolic period. The use of the double faecal marking system enables us to calculate the faecal calcium in two ways. First a value is obtained for the faecal calcium between the carmine marker and without correction for chromium recovery. Then the chromium recovery is used to correct the results for bad carmine marking and for faecal losses. Two corresponding values, the corrected and uncorrected, can then be obtained for net calcium absorption.

Values for net secreted calcium are obtained by subtracting the net calcium absorption from the true calcium absorption. Again, both corrected and uncorrected values can be obtained, depending upon which value is used for faecal calcium. It must be made clear that net secreted calcium differs from true secreted calcium by the part of the secreted calcium which is reabsorbed. It is reasonable to suppose that the calcium secreted in saliva (Schmidt, 1945) is available for absorption, while that secreted into the colon is not available. Most of the calcium secretion probably takes place in the bile and succus entericus, and we do not know how much of this is available for absorption. We do not need this information, however, for calculating either true calcium absorbed or net secreted calcium.

\section{Results}

Fig. 1 shows the values obtained for net secreted calcium both with and without the correction for chromium marker. An analysis of the means and standard deviations of these values is given in the Table.

Figs. 2 and 3 show the correlations between net and true calcium absorption without and with the chromium correction respectively. Figs. 4 and 5 show the correlations between the true calcium absorption and net calcium absorption corrected for chromium when the ${ }^{47} \mathrm{Ca}$ was given as a single dose and in the day's milk respectively.

No correlation could be found between the net secreted calcium and the calcium content of the diet, the true calcium absorbed, or the plasma calcium. 


\section{Discussion}

The correlation between true and net calcium absorptions (Figs. 2 and 3) was greatly increased when values for faecal calcium were corrected for chromium content. This provides further justification for the use of the chromium marking system. The correlation between true and net calcium absorption was much better when the ${ }^{47} \mathrm{Ca}$ was given as a single dose than when fractionated in the day's milk (Figs. 4 and 5). This rather surprising difference between the two groups is, however, mainly due to three points in Fig. 5 which we suspect may be anomalous (see below), and if these points are discarded the resultant regression line is much closer to that of Fig. 4. Further work may narrow the statistical difference between the two groups. Meanwhile the results in Fig. 4 are considered satisfactory, the correlation coefficient being as high as 0.95 ,

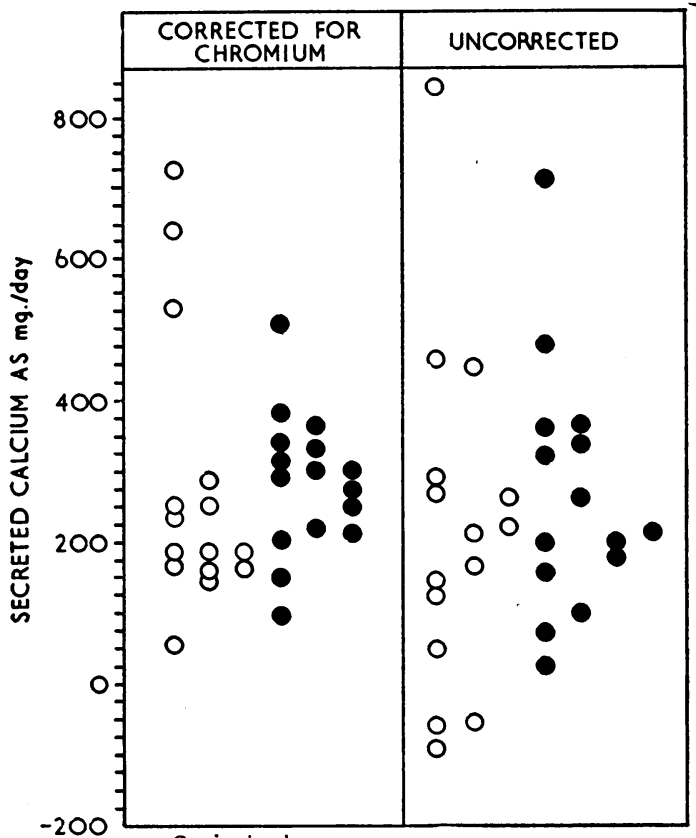

FIG. 1.-Net secreted calcium calculated with and without correction for faecal chromium recoveries. Single dose. O In day's milk.

Means and Standard Deviations for the Values of Secreted Calcium Obtained by the Various Techniques

\begin{tabular}{|c|c|c|c|}
\hline & $\begin{array}{l}\text { Type and No. of } \\
\text { Tests }\end{array}$ & $\begin{array}{l}\text { Mean } \\
\text { Secreted Ca } \\
\text { (mg./day) }\end{array}$ & S.D. \\
\hline Corrected for chromium .. & $\begin{array}{l}\text { Single dose } \\
\text { In milk }(15) \\
\text { Both together (31) }\end{array}$ & $\begin{array}{l}287 \\
277 \\
282\end{array}$ & $\begin{array}{r}95 \\
175 \\
140\end{array}$ \\
\hline Uncorrected for chromium & $\begin{array}{l}\text { Single dose }(15) \\
\text { In milk }(16) \\
\text { Both together (31) }\end{array}$ & $\begin{array}{l}226 \\
217 \\
221\end{array}$ & $\begin{array}{l}211 \\
232 \\
221\end{array}$ \\
\hline
\end{tabular}

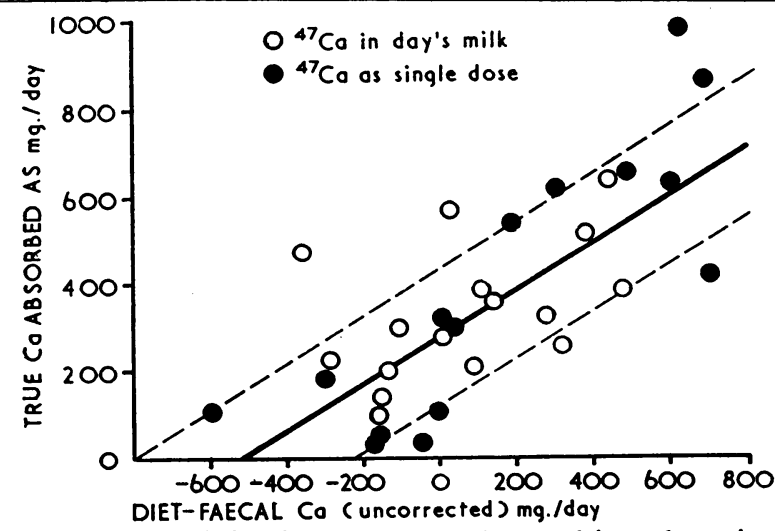

FIG. 2.-Correlation between true and net calcium absorption for all tests but without correction for faecal chromium recoveries. Here, and in the remaining figures, the solid line is the regression line, while the dotted lines represent one standard deviation from the mean. Correlation coefficient 0.76 ; slope 0.53 . and the slope of the regression line 1.05, indicating that secreted calcium is independent of absorption as expected from the work of Visek et al. (1953) and Cramer (1963).

The Table summarizes the values for secreted calcium. They are slightly higher when corrected for chromium, presumably due to inevitable faecal losses, previously assessed at about $7 \%$ (Rose, 1964). A more striking effect of the chromium corrections is the significantly inproved standard deviation from 221 (uncorrected) to 140 (corrected) mg./day, and still further reduced to $95 \mathrm{mg}$./day for single-dose administration alone. Therefore, if the net calcium absorption was calculated by subtracting $287 \mathrm{mg}$./day (mean net secreted calcium) from the true absorption obtained from a ${ }^{47} \mathrm{Ca}$ single-dose test, the result

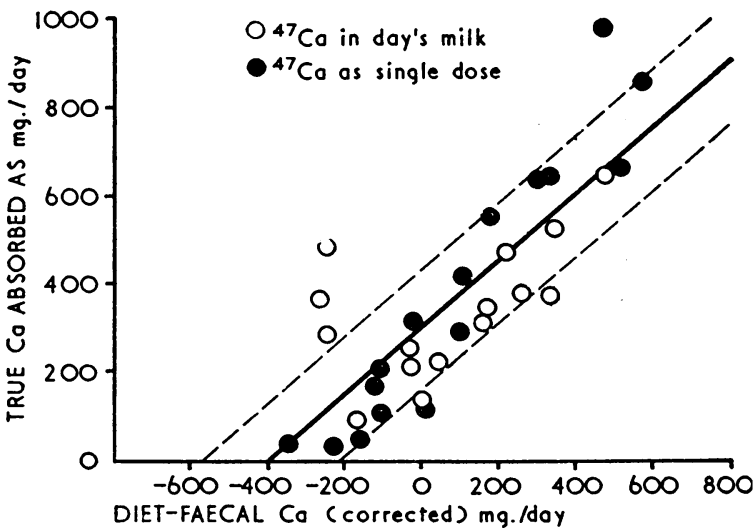

FIG. 3.-Correlation between true and net calcium absorption for all tests using corrections for chromium recoveries. Correlation coefficient 0.92 ; slope 0.96 .

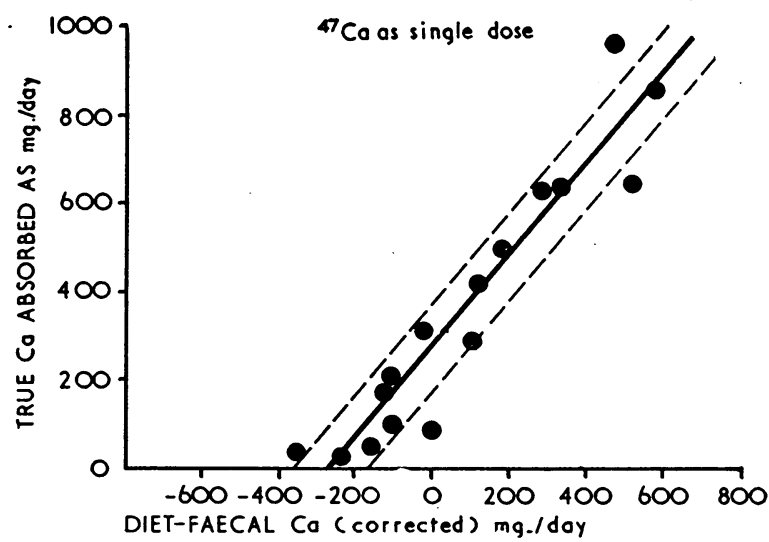

Fig. 4.-Correlation between true and net calcium absorption in those tests where ${ }^{47} \mathrm{Ca}$ was given as a single dose, and with corrections for chromium recoveries. Correlation coefficient

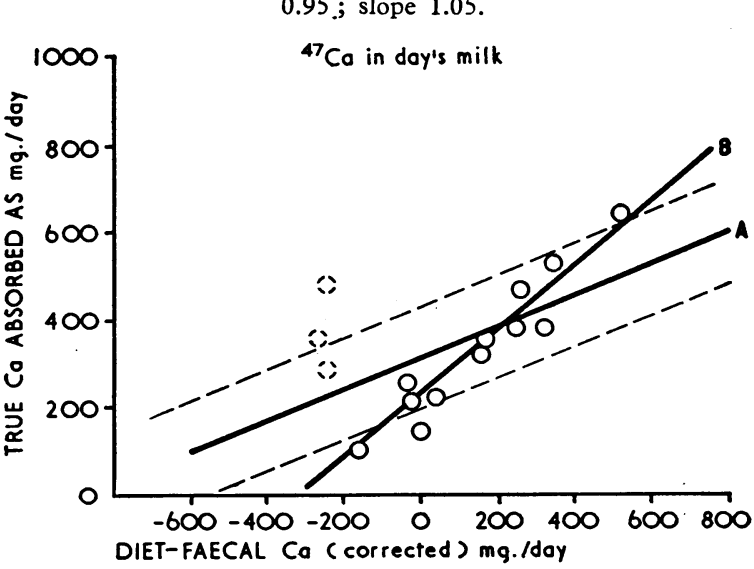

Fig. 5.-Correlation between true and net calcium absorption in those tests where ${ }^{47} \mathrm{Ca}$ was given in the day's milk ration, and with corrections for chromium recoveries. All points were used to calculate regression line $\mathbf{A}$; correlation coefficient 0.56 ; slope 0.32 . To calculate line $B$ the three points indicated by the broken circles were omitted from the calculation; correlation coefficient 0.95 ; slope $\mathbf{0 . 8 2}$. 
would be unlikely to differ by more than $190 \mathrm{mg}$./day from the net calcium absorption measured by balance technique. Some of this difference would be due to errors in the balance technique, and it seems that the isotopic derivation of net calcium absorption would be as accurate as the balance measurements. On the other hand, since three patients showed net secreted calcium values apparently above the normal range, large errors might occasionally occur in determining net calcium absorption in such a way.

Of the three patients with high values for net secreted calcium, two may have been affected by artifacts. Thus one was excessively constipated, causing abnormally long retention of ${ }^{47} \mathrm{Ca}$ in the bowels, while the second showed rather low recovery of chromium and some radioactive stools may have been lost. The third patient may indeed have had a high net secreted calcium, since she was tested twice and gave the very high values on both occasions (528 and $640 \mathrm{mg}$./day). She was unique in our series in several other respects, having the highest faecal fat, primary biliary cirrhosis, portal hypertension, and a high basal metabolic rate.

It is concluded that, while net secreted calcium is reasonably constant in most of the patients studied, notable exceptions can occur and only further experience can reveal just how common these exceptions may be. It might be surmised that cases of protein-losing enteropathy will show high net secreted calcium, but there may be other causes.

The relative constancy of net calcium secretion in most of the cases seems surprising, for if the secreted calcium is available for absorption the net secretion should vary with the degree of ${ }^{47} \mathrm{Ca}$ absorption. No such correlation could be demonstrated, and two deductions may therefore be made. Firstly, when the true calcium absorption is very small the net secretion approximates to the true secretion of about 287 mg./day. Secondly, there must be negligible absorption of the secreted calcium, even when the absorption of dietary calcium is normal or high. The latter suggests that absorption of dietary calcium must take place high up in the jejunum or duodenum. There is little information available on the site of absorption of dietary calcium in man, though Lengemann (1963) showed in rats a progressively slower rate of absorption on passing from duodenum to ileum.

Nine of the patients studied had osteomalacia due to chronic renal failure (three patients), steatorrhoea (three patients), and renal tubular hypophosphataemia (three patients). Ten patients had osteoporosis due to various causes and one had primary hyperparathyroidism. Many either had raised faecal calcium or had had raised faecal calcium prior to therapy with vitamin $\mathrm{D}$. Yet, with only the one definite exception discussed above, the cause of the high faecal calcium was shown to be due to failure to absorb calcium and not to a rise in calcium secreted into the gastro-intestinal tract.

The present series of radioisotope tests for absorption of calcium has been shown to give consistent and reliable results in an extensive trial. Earlier radioactive tests for calcium absorption-for example, Bhandarkar et al. (1961) and Jaworski et al. (1963)-adopted different and less rigid criteria. Cameron et al. (1962) carried out studies similar to ours on four patients, but without continuous chromium marking. The values for net secreted calcium as calculated from their data are $210,52,109$, and $445 \mathrm{mg}$./day, reasonably close to our values. Samachson (1963) used an elegant but technically more difficult method, and did not compare his results with the traditional calcium-balance technique.

In calculating the calcium secreted into the bowel, most other workers have assumed complete mixing of digestive juice and dietary calcium prior to absorption. Blau et al. (1957) derived values of 150 and $360 \mathrm{mg}$./day for total digestive juice calcium and about $100 \mathrm{mg}$./day for endogenous faecal calcium, both values being unaffected by calcium intake. Nordin et al. (1962), using intravenous doses of radio-calcium, calculated a mean value of $175 \mathrm{mg}$./day for endogenous faecal calcium. If it is true, however, that there is negligible absorption of secreted calcium, then the figures obtained by these workers may need modification.

The combination of the ${ }^{47} \mathrm{Ca}$ test with the conventional calcium balance is proving valuable in measuring the true calcium absorption from and secretion into the bowel. If it is confirmed that only occasional cases have abnormally high secreted calcium, then it may be possible to use the radioactive calcium absorption test as an alternative to the traditional calcium-balance technique and so eliminate handling and processing of stools. The main obstacle at present is that with the sensitivity of our apparatus we have to restrict the number of tests to two per patient. However, when a new design of counter for measurement of faecal radioactivity is completed we hope to reduce considerably the dose per test and so make possible repeated studies where desired.

\section{Summary}

In a series of patients with disorders of calcium metabolism the net calcium absorption calculated by subtracting faecal from dietary calcium has been compared with true calcium absorption derived from measuring faecal excretion of orally administered ${ }^{47} \mathrm{Ca}$. Continuous chromium marking of stools was used to increase accuracy of faecal calcium measurements. The correlation between net and true calcium absorption was greatly improved when the faecal calcium was corrected for chromium excretion. The ${ }^{47} \mathrm{Ca}$ was given either as a single shot with the breakfast or in the patient's milk ration for the day. Correlation between true and net calcium absorption was much better when the ${ }^{47} \mathrm{Ca}$ was given as the single shot.

The difference between true and net calcium absorption is the net secreted calcium, which seems to be virtually equal to the true secreted calcium. This secreted calcium is not raised in the metabolic conditions most commonly associated with raised faecal calcium. For many purposes this oral ${ }^{47} \mathrm{Ca}$ test could be used as an alternative to the traditional calcium balance as a means of finding net calcium absorption, although there might be occasional anomalies. There need be no handling or chemical manipulation of the stools.

We are grateful to the nursing, dietetic, and technical staff of the metabolic unit for continual co-operation, which is essential for this type of work. The chemical analyses were carried out by Miss V. Grayson, Mr. D. Newton, and Mrs. A. Spencer. We are grateful to Dr. C. J. Hayter for the use of counting equipment and for counting assistance from Miss S. Bartlett and Mr. M. Elliott.

\section{REFERENCES}

Bellin, J., and Laszlo, D. (1953). Science, 117, 331.

Bhandarkar, S. D., Bluhm, M. M., MacGregor, J., and Nordin, B. E. C. (1961). Brit. med. F., 2, 1539 .

Blau, M., Spencer, H., Swernov, J., Greenberg, J., and Laszlo, D. (1957). 7. Nutr., 61, 507 .

Bronner, F., Harris, R. S., Maletskos, C. J., and Benda, C. E. (1956). F. clin. Invest., 35, 78 .

Cameron, J. S., Butterfield, W. J. H., Veall, N., Rees, J. R., and Parsons, V. (1962). Medical Uses of $\mathrm{Ca}^{47}$; Technical Reports Series No. 10 of the International Atomic Energy Agency, Vienna, p. 29.

Cramer, C. F. (1963). In The Transfer of Calcium and Strontium Across Biological Membranes, edited by R. H. Wasserman. Academic Press, New York and London.

Geissberger, W. (1952). Z. ges. exp. Med., 119, 111.

Jaworski, Z. F., Brown, E. M., Fedoruk, S., and Seitz, H. (1963). New Engl. f. Med., 269, 1103.

Lengemann, F. W. (1963). In The Transfer of Calcium and Strontium Across Biological Membranes, edited by R. H. Wasserman. Academic Press, New York and London.

Nordin, B. E. C., Bluhm, M., and MacGregor, J. (1962). In Radioisotopes and Bone, edited by F. C. McLean, p. 123. Blackwell, Oxford.

Rose, G. A. (1964). Gut, 5, 274.

Samachson, J. (1963). Clin. Sci., 25, 17.

Schmidt, N. B. (1945). Acta Physiol. scand., 9, 166.

Schmidt, N. B. (1945). Acta Physiol. scand., 9, 166. 2.

Visek, W. J., Monroe, R. A., Swanson, E. W., and Comar, C. L. (1953). f. Nutr., 50, 23. 